\title{
Thermo-environomic optimisation strategy for fuel decarbonisation process design and analysis
}

\author{
Laurence Tock $^{\mathrm{a}, *}$, François Maréchal ${ }^{\mathrm{a}}$ \\ ${ }^{a}$ Industrial Process and Energy Systems Engineering, Ecole Polytechnique Fédérale de Lausanne, \\ Station 9, CH-1015 Lausanne, Switzerland
}

\begin{abstract}
To meet the $\mathrm{CO}_{2}$ reduction targets and ensure sustainable energy supply, the development and deployment of cost-competitive innovative low-carbon energy technologies is essential. To design and evaluate the competitiveness of such complex integrated energy conversion systems, a systematic thermo-environomic optimisation strategy for the consistent modelling, comparison and optimisation of fuel decarbonisation process options is developed. The environmental benefit and the energetic and economic costs are assessed for several carbon capture process options. The performance is systematically compared and the trade-offs are assessed to support decision-making and identify optimal process configurations with regard to the polygeneration of $\mathrm{H}_{2}$, electricity, heat and captured $\mathrm{CO}_{2}$. The importance of process integration in the synthesis of efficient decarbonisation processes is revealed. It appears that different process options are in competition when a carbon tax is introduced. The choice of the optimal configuration is defined by the priorities given to the different thermo-environomic criteria.
\end{abstract}

Keywords: $\mathrm{CO}_{2}$ capture and storage, biomass, power plant, process design, energy integration, multi-objective optimisation.

\section{Nomenclature}

\section{Abbreviations}

ATR Autothermal Reforming

BM Biomass

CAP Chilled Ammonia Process

CC Carbon Capture

*Phone: +41216933528 Fax: +41 216933502

Email addresses: laurence.tock@epfl.ch (Laurence Tock), francois.marechal@epfl.ch (François Maréchal) 
CCS Carbon Capture and Storage

FU Functional Unit

FICFB Fast Internally Circulating Fluidised Bed

GWP Global Warming Potential

IPCC International Panel on Climate Change

LCA Life Cycle Assessment

LCIA Life Cycle Impact Assessment

MEA Monoethanolamine

MILP Mixed Integer Linear Programming

MINLP Mixed Integer Non-Linear Programming

NG Natural Gas

NGCC Natural Gas Combined Cycle

PSA Pressure Swing Adsorption

RME Rape Methyl Ester

SMR Steam Methane Reforming

TEA Triethanolamine

\section{Greek letters}

$\Delta h^{o} \quad$ Lower heating value, $\mathrm{kJ} / \mathrm{kg}$

$\epsilon \quad$ Energy efficiency, \%

\section{Roman letters}

COE Electricity production cost, $\$ / \mathrm{GJ}_{e}$

$\dot{E} \quad$ Mechanical/electrical power, $\mathrm{kW}_{e}$

$\dot{m}$ Mass flowrate, $\mathrm{kg} / \mathrm{s}$

$\dot{n} \quad$ Molar flowrate, $\mathrm{kmol} / \mathrm{s}$

$\dot{Q} \quad$ Heat, $\mathrm{kW}$

\section{Superscripts}

$+\quad$ Material/energy stream entering the system

- $\quad$ Material/energy stream leaving the system

\section{Introduction}

To meet the challenges of climate change mitigation and sustainable energy supply, several proposals have been investigated, particularly since the Kyoto Protocol in 1997, 
such as reducing the energy consumption, improving the energy efficiency, changing to less carbon intensive fuels and finally switching to renewable fuels. In the short to medium term, $\mathrm{CO}_{2}$ emissions reduction by carbon capture and storage (CCS), is considered as a promising option for power plants applications. Three major concepts can be distinguished for $\mathrm{CO}_{2}$ capture: post-, pre- and oxyfuel-combustion [1].

Post-combustion $\mathrm{CO}_{2}$ capture consists in the end-of-pipe separation of the $\mathrm{CO}_{2}$ from the flue gas of fuel combustion. In oxy-fuel combustion pure oxygen is used for the combustion yielding a flue gas containing mainly $\mathrm{CO}_{2}$ and water which is removed by condensation. In pre-combustion $\mathrm{CO}_{2}$ capture the $\mathrm{CO}_{2}$ is separated after the gasification and reforming of fuel and the remaining $\mathrm{H}_{2}$ is used in a gas turbine to generate electricity.

Potential technologies for separating the $\mathrm{CO}_{2}$ from the other gases are chemical absorption, physical ab- and adsorption and membrane processes. A detailed review of the different technologies is reported in [2]. In predictions for post 2020 scenarios from the European Union [3] and the International Energy Agency [4], CCS is regarded as costcompetitive compared to other low-carbon alternatives including wind and solar power. The thermo-economic competitiveness of the different $\mathrm{CO}_{2}$ capture options depends on the power cycle, the resources, the capture technology and the economic scenario [5]. The current status of the development of $\mathrm{CO}_{2}$ capture technologies is reviewed in [6]. $\mathrm{CO}_{2}$ capture reduces the environmental impact on the one hand but on the other hand the power generation efficiency is decreased by up to $10 \%$-points and the production costs are increased by over $30 \%$ due to the additional energy requirement and equipment costs for $\mathrm{CO}_{2}$ capture and compression. The penalty of $\mathrm{CO}_{2}$ capture in terms of efficiency and costs has been evaluated by the European Technology Platform [7],the International Panel on Climate Change [1] and the International Energy Agency [4]. By applying process modelling and simulations, different process configurations for producing $\mathrm{H}_{2}$ [8] and/or electricity [9] have been evaluated considering considering natural gas [10], coal and/or biomass resources $[11,12]$. These studies mainly focus on the thermodynamic performance without including detailed heat and power integration. The advantages of process integration of $\mathrm{CO}_{2}$ capture options are investigated by [13]. Economic aspects of $\mathrm{CO}_{2}$ capture are considered in [14] for coal power plants and in [15] for plants fed with fossil or renewable resources. Environmental aspects are taken into account in [16] and a detailed life cycle assessment of CCS in power and hydrogen plants is performed 
in [17] respectively in [18]. However, none of these studies combines extensive flowsheeting with thermodynamic, economic and environmental considerations simultaneously to make a comprehensive comparison of $\mathrm{CO}_{2}$ capture options in $\mathrm{H}_{2}$ and power production applications.

To overcome the difficulties of comparing processes with regard to multiple criteria and different assumptions, the goal is to propose a comprehensive comparison framework for the quantitative and consistent comparison and optimisation of process options. The objective is to develop and apply a uniform methodology for the systematic comparison and optimisation of different fuel decarbonisation process configurations. By combining thermo-economic models, energy integration techniques, and economic and environmental performance evaluations simultaneously, the platform based on computer-aided tools will support the decision-making process for $\mathrm{H}_{2}$ and fuel decarbonisation process development, design and operation with regard to several criteria. Special interest is given to the effect of polygeneration of $\mathrm{H}_{2}$ fuel, captured $\mathrm{CO}_{2}$, heat and power, in order to identify its advantages and constraints. Through multi-objective optimisation the trade-off between efficiency, $\mathrm{CO}_{2}$ capture rate and costs is assessed. The potential process improvement of $\mathrm{CO}_{2}$ capture process integration by internal heat recovery and valorisation of waste heat for combined heat and power generation is investigated. Taking into account the sensitivity of the economic performance to the carbon tax, resource price, operating time, investment and interest rate, it is studied how the optimal process design is influenced by the economic scenario and a decision support approach is proposed.

\section{Thermo-environomic optimisation methodology}

The process design methodology combines process modelling, using established flowsheeting tools, and process integration models in a multi-objective optimisation framework following the approach presented in [19] and extended with LCA in [20]. The main features of the methodology are summarised in Figure 1 and the main steps are specified hereafter.

Technology models representing the physical behaviour are separated from the thermoeconomic analysis models and the multi-objective optimisation including energy integration, economic evaluation and environmental impact assessment. Through a MATLABlanguage [21] based platform, structured data is transferred between the different models. 


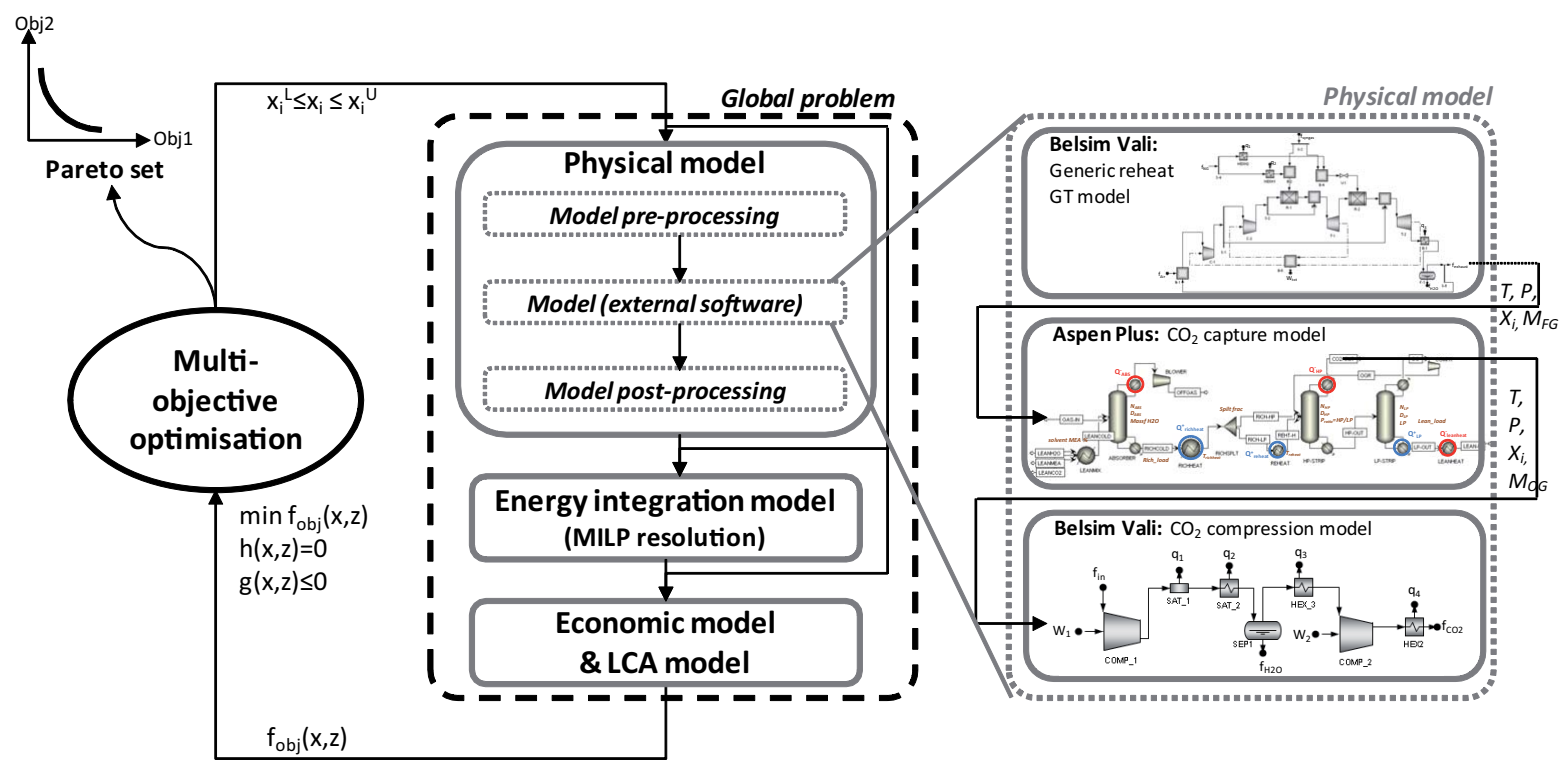

Figure 1: Illustration of the developed platform for studying energy conversion systems.

The advantage of dissociating the technology models from the analysis models is that process unit models developed with different software can be assembled in a superstructure for subsequent large processes design and optimisation[22]. Moreover, by including the process integration model in the design process the influence of the design and operation is reflected on the thermo-environomic performance of an energy balanced system. The trade-off between the competing objectives, like investment, emissions or energy efficiency, is assessed by multi-objective optimisation simultaneously optimising several objectives with regard to the decision variables (i.e. technology selection and operating conditions). The optimization including discrete and continuous variables, as well as linear and non-linear relationships it is a Mixed Integer Non-Linear Programming (MINLP) problem, which is in this work divided into two sub-problems, namely a master and a slave problem. The master optimisation for example maximises the energy efficiency and minimises the cost, respectively the environmental performance with regard to the process operating conditions (i.e. temperature, pressure,...). An evolutionary algorithm [23] implemented in Matlab is applied to solve the Master optimisation problem and generate a set of optimal solutions (i.e. Pareto frontier) and define the values of decision variables for the most promising configurations. The slave optimisation problem corresponds to the energy integration MILP problem which minimizes the operating cost under the heat 
and power cascade constraints as detailed here below.

\subsection{Process modelling}

The fist step consists in the development of a physical model of the system of interest. A block flow diagram of the studied conversion process is set up and suitable technologies are summarised in a superstructure, like the one illustrated in Figure 2 for pre-combustion $\mathrm{CO}_{2}$ capture options. The data collection and the definition of the input parameters of the superstructure is part of the pre-processing step.

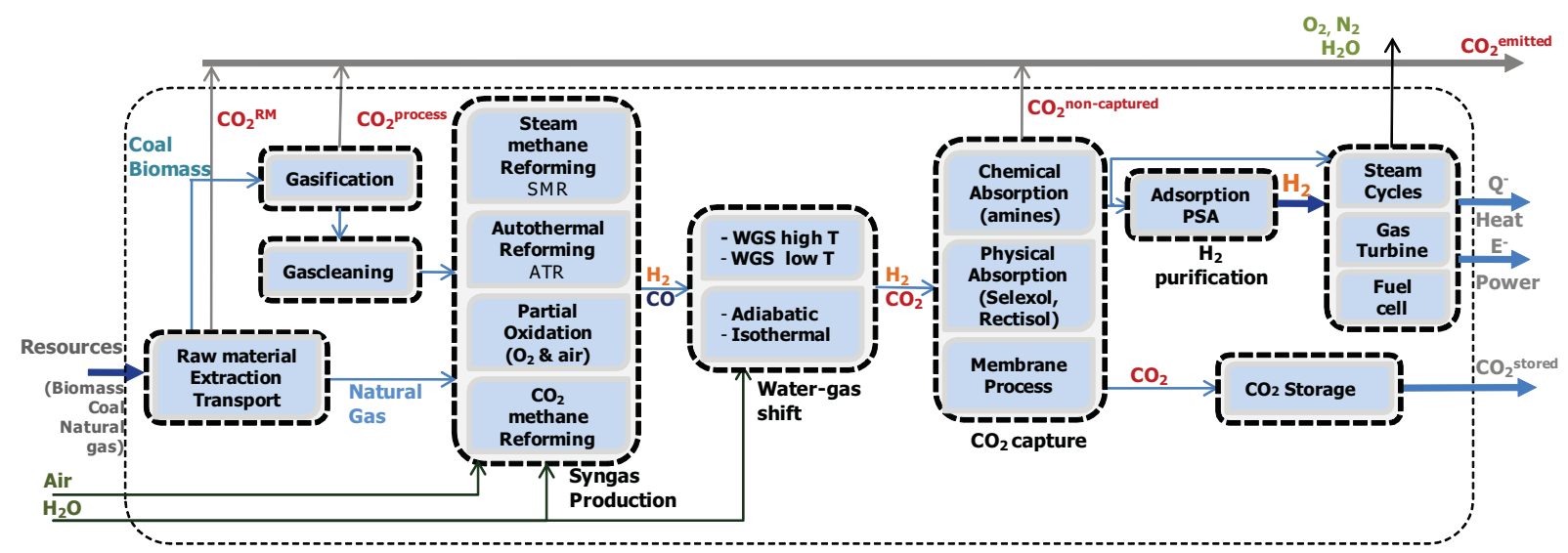

Figure 2: Process superstructure of pre-combustion $\mathrm{CO}_{2}$ capture process options.

For each process unit, chemical and physical models are developed and the heat transfer requirement is defined by using conventional flowsheeting software such as Belsim Vali [24] and Aspen Plus [25]. Data such as temperatures, pressures, mass and heat flows are extracted from the process models (post-processing) and sent to the next computing step.

\subsection{Energy Integration}

In the energy integration model, the optimal thermal process integration is computed for a fixed plant size and consequently for a given energy demand. The pinch analysis concept is applied to minimise the energy consumption of the process by calculating thermodynamically feasible energy targets and achieving them by optimising the heat recovery and the combined heat generation. The problem is solved as a Mixed Integer Linear Programming Problem (MILP) minimising the operating costs, while computing the mass balances and the heat cascade as explained in [26]. The heating and cooling requirements are assessed considering minimum approach temperatures $\left(\Delta T_{\min }\right)$ of 2 
$\mathrm{K}, 4 \mathrm{~K}$ and $8 \mathrm{~K}$ for phase-changing, liquid and gas streams respectively. The selection and use of the utilities (e.g. cooling by river water or refrigeration cycle) are optimized and the integration of the steam network is optimized (i.e. flowrates of the headers) to valorize the excess heat by cogeneration of electricity. The MILP energy integration problem (slave) is solved as a subproblem of the master optimisation. The slave optimisation defines thus the best possible layout of the process and heat exchanger network for given operating conditions defined by the master optimisation. The detailed heat exchanger network design is not systematically generated for each solution, but could be computed subsequently.

\subsection{Performance evaluation}

In the performance evaluation step the emissions, size and equipment costs of the system are estimated based on the flows and operating conditions computed in the previous steps. The performance of the system is characterized by different performance indicators taking into account energetic, economic and environmental considerations.

\subsubsection{Economic performance}

For the economic evaluation the costs are estimated based on equipment sizing and cost correlations from literature $[27,28]$. The total costs are defined by the annualized capital investment and the annual operating costs based on the base case assumptions reported in Table 9 .

\subsubsection{Environmental impact assessment}

The environmental impacts are evaluated by the approach described in [20] including life-cycle assessment (LCA) in the thermo-economic model. Following the cradle-to-gate approach, the environmental impact evaluation takes into account the influence of the process design and operation (i.e. consequential LCA). In the life cycle inventory phase every flow, crossing the system boundaries as an extraction or an emission, which is necessary to one of the unit processes, is identified and quantified based on the process layouts. The life cycle inventory data are based on the reference data-sets from Ecoinvent [29] for a Swiss-European context. The major process steps are resource extraction, syngas production, gas treatment and $\mathrm{CO}_{2}$ removal, and heat and power generation. In this study the impacts are evaluated for the production of 1 GJ of electricity (i.e. functional unit FU 
$\left.=1 \mathrm{GJ}_{e}\right)$. The environmental impact is assessed with different impact methods to address the influence on greenhouse gas emissions, ecosystem, human health and resources. The method of the International Panel on Climate Change (IPCC) 2007 ([30]) is used to calculate the global warming potential in terms of equivalent $\mathrm{CO}_{2}$ emissions on a 100 years time-horizon. It has to be noted that the GWP of fossil $\mathrm{CO}_{2}$ emissions is standardised to 1, while for biogenic $\mathrm{CO}_{2}$ emissions the GWP is considered as 0. Storage of fossil $\mathrm{CO}_{2}$ accounts as zero to GWP, while storage of biogenic $\mathrm{CO}_{2}$ leads to a GWP of -1 . The negative balance is due to the fact that the released $\mathrm{CO}_{2}$ was previously fixed in the plant as hydrocarbon by photosynthesis. In addition to the climate change impact (CCI), the impacts on resources (Res), human health (HH) and ecosystem quality (EQ) are evaluated by the Impact 2002+ method (endpoint categories) and the damage-oriented Ecoindicator-99-(h,a) method (hierarchist perspective, single score) . In the Ecoindicator99 method [31] climate change is accounted in the human health impact aggregating also carcinogenic, ozone layer depletion and respiratory effects. The respective weighting factors are for the Ecoindicator-99 method $40 \% \mathrm{HH}, 40 \% \mathrm{EQ}$ and $20 \%$ Res.

\subsubsection{Performance indicators}

The competitiveness is evaluated by the energy and cost penalty and the environmental benefit of capturing $\mathrm{CO}_{2}$ in power plants. The thermodynamic performance is evaluated by the first law energy efficiency $\epsilon_{t o t}$ (Eq.1) expressed by the ratio between the net electricity output $\left(\Delta \dot{E}^{-}=\dot{E}^{-}-\dot{E}^{+}\right)$and the thermal energy input of the resources. The energy efficiency is expressed on the basis of the lower heating value $\left(\Delta h^{0}\right.$, LHV). To assess the $\mathrm{CO}_{2}$ mitigation potential, the $\mathrm{CO}_{2}$ capture rate is defined in Eq.2 by the molar ratio between the $\mathrm{CO}_{2}$ captured and the carbon entering the system. The environmental benefit is expressed by the local $\mathrm{CO}_{2}$ emissions and the overall life cycle impacts assessed for different impact methods for a functional unit of 1GJ of electricity produced. The $\mathrm{CO}_{2}$ capture cost is evaluated by the $\mathrm{CO}_{2}$ avoidance costs, which are expressed in Eq.3 by the difference of the emissions and the difference of the total production cost with regard to a reference plant without $\mathrm{CO}_{2}$ capture (i.e. a conventional natural gas combined cycle (NGCC) power plant without $\mathrm{CO}_{2}$ capture). The economic performance is evaluated by the capital investment and the production costs with the economic assumptions defined in Table 9. 


\subsubsection{Decision making}

The multi-objective optimisation yields a set of optimal solutions, i.e. Pareto frontiers from which it is not obvious which specific solution has to be selected, as each solution is optimal with regard to the chosen objective. In order to support decision making based on the Pareto-optimal solutions a method that takes into account the economic parameter sensitivity is applied. The method has been developed in [32]. The fluctuation of the economic conditions, such as resource price or carbon tax, are first described by probability distribution functions. Then the decision criteria (for example COE including carbon tax) is recomputed for each Pareto solution for a multitude of economic scenarios characterized each by a set of economic parameters randomly generated from the distribution functions. Finally, the process designs are ranked and the most economically competitive design is identified based on probability calculations.

\section{Process description}

To assess the impact of the $\mathrm{CO}_{2}$ capture concept and technology on the competitiveness of $\mathrm{H}_{2}$ and/or electricity production processes, the different process options illustrated in Figures 2 and 3 are investigated. Natural gas (NG) and biomass (BM) (i.e wood characterised by a weight composition of $51.09 \% \mathrm{C}, 5.75 \% \mathrm{H}, 42.97 \% \mathrm{O}$ and $0.19 \% \mathrm{~N}$, and a humidity of $50 \%$ wt) are considered as a resource. Coal applications have been studied separately in [33]. The captured $\mathrm{CO}_{2}$ is compressed to 110 bar for subsequent transport and storage. The models and some specific results have been previously published in $[34,35]$ for $\mathrm{H}_{2}$ production and in [36] for power plants applications. It is focused here essentially on the competitiveness assessment of the electricity production processes with $\mathrm{CO}_{2}$ capture illustrated in Figure 3. The decision variables of the different power plants are summarized in Table 1.

\section{1. $\mathrm{CO}_{2}$ capture models}

The investigated technologies for $\mathrm{CO}_{2}$ capture are for post-combustion $\mathrm{CO}_{2}$ capture:

- Chemical absorption with monoethanolamine (MEA)

- Chemical absorption with chilled ammonia (CAP)

and for pre-combustion $\mathrm{CO}_{2}$ capture: 

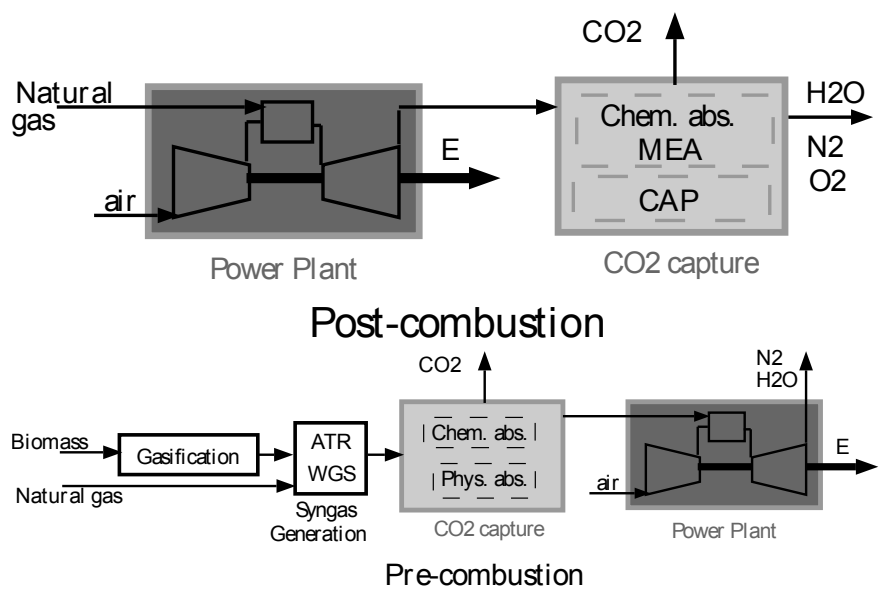

Figure 3: Investigated $\mathrm{CO}_{2}$ capture options for electricity production.

Table 1: Decision variables for the natural gas and biomass fed power plants.

\begin{tabular}{llr}
\hline Section & Specification & Range \\
\hline Biomass drying & $\mathrm{T}[\mathrm{K}]$ & 473 \\
Biomass pyrolysis & $\mathrm{T}[\mathrm{K}]$ & 533 \\
Biomass gasification & $\theta_{\text {wood,gasif_in }}[\% \mathrm{wt}]$ & {$[5-35]$} \\
& $\mathrm{T}[\mathrm{K}]$ & {$[1000-1200]$} \\
& $\mathrm{P}[\mathrm{bar}]$ & {$[1-15]$} \\
SMR after gasification & $\mathrm{T}[\mathrm{K}]$ & {$[950-1200]$} \\
ATR & $\mathrm{T}[\mathrm{K}]$ & {$[780-1400]$} \\
& $\mathrm{P}[\mathrm{bar}]$ & {$[1-30]$} \\
WGS & $\mathrm{S} / \mathrm{C}[-]$ & {$[0.5-6]$} \\
& $\mathrm{T}_{H T S}(\mathrm{NG} / \mathrm{BM})[\mathrm{K}]$ & {$[523-683] /[573-683]$} \\
& $\mathrm{T}_{\text {LTS }}(\mathrm{NG} / \mathrm{BM})[\mathrm{K}]$ & {$[423-523] /[423-573]$} \\
& $\mathrm{P}(\mathrm{BM})[\mathrm{bar}]$ & {$[1-25]$} \\
NGCC plant & $\mathrm{S} / \mathrm{C}(\mathrm{BM})[-]$ & {$[0.2-4]$} \\
& $\mathrm{FGR}[-]$ & {$[0-0.56]$} \\
\hline
\end{tabular}

- Chemical absorption with triethanolamine (TEA)

- Physical absorption with Selexol

The chemical absorption with MEA is modelled in Aspen Plus based on the model presented in [36] consisting of an adsorber and a dual-pressure stripper as described in [37]. In the thermodynamic model, the electrolyte NRTL method is used for the liquid phase and the Redlich-Kwong method for the vapour phase. The absorber and desorber are modelled as rate based RadFrac columns including reaction kinetics. The $\mathrm{CO}_{2}$ capture rate is defined by the columns design (i.e. number of stages, diameter, etc.) and the operating conditions summarized in Table 2. 
Table 2: Decision variables for the chemical absorption process with monoethanolamine.

\begin{tabular}{lc}
\hline Operating parameter & Range \\
\hline Lean solvent $\mathrm{CO}_{2}$ loading $[\mathrm{kmol} / \mathrm{kmol}]$ & {$[0.18-0.25]$} \\
Rich solvent $\mathrm{CO}_{2}$ loading $[\mathrm{kmol} / \mathrm{kmol}]$ & {$[0.4-0.5]$} \\
Rich solvent pre-heat T $\left[{ }^{\circ} \mathrm{C}\right]$ & {$[95-105]$} \\
Rich solvent re-heat T $\left[{ }^{\circ} \mathrm{C}\right]$ & {$[115-125]$} \\
LP stripper pressure $[\mathrm{bar}]$ & {$[1.7-2.1]$} \\
$\mathrm{HP} / \mathrm{LP}$ pressure ratio $[-]$ & {$[1-1.5]$} \\
MEA \% in solvent $[-]$ & {$[0.3-0.35]$} \\
Absorber steam out $\left[\mathrm{kg}_{H 2 O} / \mathrm{t}_{F G}\right]$ & {$[306-309.5]$} \\
Split fraction $[-]$ & {$[0-0.7]$} \\
Nb stages absorber & {$[10-17]$} \\
Nb stages HP stripper & {$[8-15]$} \\
Nb stages LP stripper & {$[6-10]$} \\
Absorber diameter $[\mathrm{m}]$ & {$[6-12]$} \\
HP stripper diameter $[\mathrm{m}]$ & {$[3-6]$} \\
LP stripper diameter $[\mathrm{m}]$ & {$[2-5]$} \\
\hline
\end{tabular}

While chemical absorption with MEA is suited for capturing $\mathrm{CO}_{2}$ from flue gas, TEA is more appropriate to separate $\mathrm{CO}_{2}$ from a $\mathrm{H}_{2}$-rich fuel. The model is adapted from the default rate-based model available from AspenTech [25]. The absorber is modelled by an equilibrium RadFrac column and the desorber by a single stage flash unit. The lean solvent recycling is not modelled explicitly, but by imposing design specifications it is ensured that the streams are identical after solvent make-up. The main decision variables are summarised in Table 3.

Table 3: Decision variables for the chemical absorption process with TEA.

\begin{tabular}{lr}
\hline Operating parameter & Range \\
\hline TEA concentration [\%wt] & {$[25-40]$} \\
$\mathrm{H}_{2} /$ TEA ratio $[\mathrm{kg} / \mathrm{kg}]$ & {$[0.035-0.055]$} \\
Absorber T $\left[{ }^{\circ} \mathrm{C}\right]$ & {$[20-45]$} \\
Absorber P $[\mathrm{bar}]$ & {$[15-30]$} \\
Nb stages absorber & \\
Absorber packing & Pall ring \& Ralu-ring (rasching) \\
Regeneration P $[\mathrm{bar}]$ & \\
Regeneration $\mathrm{T}\left[{ }^{\circ} \mathrm{C}\right]$ & {$[1-130]$} \\
\hline
\end{tabular}

The major drawback of the chemical absorption with amines is the large energy requirement for the solvent regeneration which is in the range of 1.5-3.4 GJ/ $\mathrm{t}_{\mathrm{CO} 2}$ [1]. Instead of using amines a promising alternative is to use ammonia which satisfies some of the ideal solvent characteristics such as energy efficient $\mathrm{CO}_{2}$ capture, i.e. high $\mathrm{CO}_{2}$ absorption capacity and low regeneration energy, stable (no degradation) and globally available low-cost reagent. The chilled ammonia process (CAP) patented by [38] operates at low temperature $0-20{ }^{\circ} \mathrm{C}$. For the CAP process, the absorber and the desorber are modelled 
in Aspen Plus by a single flash stage assuming physical and chemical equilibrium. Since the $\mathrm{NH}_{3}$ slip from the absorber is in the range of 500-3000 $\mathrm{ppm}_{v}$, which is much too high for gases vented to the atmosphere, a water wash column is introduced in order to reduce the level to $10 \mathrm{ppm}_{v}$. The vent gas is heated up to around $45^{\circ} \mathrm{C}$ in order to satisfy flume conditions before being released to the atmosphere. The rich solvent passes a pump and an heat exchanger before entering the regeneration column. The temperature of the heat exchanger is defined such that all the ammonium bicarbonate is dissolved before entering the flash column in order to have no fouling issues. The cooling down below atmosphere to the absorber temperature is modelled in the energy integration by a refrigeration cycle. The decision variables are summarized in Table 4.

Table 4: Decision variables for the chilled ammonia process.

\begin{tabular}{lr}
\hline Operating parameter & Range \\
\hline $\mathrm{NH}_{3}$ concentration [\%wt] & 28 \\
$\mathrm{CO}_{2}$ capture rate [\%] & {$[85-95]$} \\
Lean $\mathrm{CO}_{2}$ loading $[\mathrm{kmol} / \mathrm{kmol}]$ & {$[0.33-0.67]$} \\
Absorber $\mathrm{T}\left[{ }^{\circ} \mathrm{C}\right]$ & {$[0-10]$} \\
Absorber P $[\mathrm{bar}]$ & 1 \\
Regeneration P $[$ bar] & {$[2-136]$} \\
\hline
\end{tabular}

Compared to chemical absorption the thermodynamic modelling of the physical absorption with Selexol is less complex since no ions are involved and no chemical reactions take place in the absorber/desorber. The model is adapted from the default models for physical solvents available from AspenTech [25]. To model the thermo-physical properties the PC-SAFT equation of state model for vapour pressure, liquid density, heat capacity and phase equilibrium is used. The absorber is modelled as a RadFrac column and the desorber as a single stage flash unit. The $\mathrm{CO}_{2}$ capture rate is defined by the flowrate of the lean solvent and the columns design. The main decision variables of the physical absorption process are reported in Table 5.

Table 5: Decision variables for the physical absorption with Selexol solvent.

\begin{tabular}{lr}
\hline Operating parameter & Range \\
\hline DEPG $/ \mathrm{CO}_{2}$ ratio $[\mathrm{kg} / \mathrm{kg}]$ & {$[8-14]$} \\
Absorber $\mathrm{T}\left[{ }^{\circ} \mathrm{C}\right]$ & {$[-18-173]$} \\
Absorber P $[\mathrm{bar}]$ & {$[10-60]$} \\
Nb stages absorber & 10 \\
Absorber packing & Pall ring \\
Regeneration $\mathrm{P}[\mathrm{bar}]$ & {$[1-10]$} \\
Regeneration $\mathrm{T}\left[{ }^{\circ} \mathrm{C}\right]$ & {$[25-100]$} \\
\hline
\end{tabular}




$$
\begin{aligned}
& \epsilon_{t o t}=\frac{\Delta \dot{E}^{-}}{\Delta h_{f e e d, i n}^{0} \cdot \dot{m}_{f e e d, i n}} \\
& \eta_{C O 2}=\frac{\dot{n}_{C_{\text {captured }}}}{\dot{n}_{C_{\text {in }}}} \cdot 100 \\
& \$ / t_{C O 2, \text { avoided }}=\frac{C_{P_{C C}}-C_{P_{r e f}}}{\dot{m}_{C O_{2, \text { emitted }_{\text {ref }}}}-\dot{m}_{C O_{2, \text { emitted }_{C C}}}} \frac{[\$ / G J]}{\left[t_{C O 2} / G J\right]}
\end{aligned}
$$

\section{Systematic comparison of $\mathrm{CO}_{2}$ capture options}

\subsection{Multi-objective optimisation}

The trade-offs between the competing objectives are assessed by multi-objective optimisation. Applying an evolutionary algorithm, the energy efficiency $\epsilon_{\text {tot }}$ and the $\mathrm{CO}_{2}$ capture rate $\eta_{\mathrm{CO} 2}$ are maximised. Based on Pareto results illustrated on Figure 4, compromise process configurations with $90 \%$ of $\mathrm{CO}_{2}$ capture are selected for natural gas fed processes and with $60 \%$ of capture for biomass fed power plants. The performance results are summarised in Table 6 and illustrated in Figure 5. The corresponding values of the decision variables are reported in Table 7 for the power plant designs with post-combustion $\mathrm{CO}_{2}$ capture and in Table 8 for the pre-combustion configu-

\begin{tabular}{|c|c|c|c|c|c|c|c|c|}
\hline System & NGCC & Post-comb & Post-comb & ATR & ATR & SMR & BM & $\mathrm{BM}$ \\
\hline Capture technology & no $\mathrm{CC}$ & MEA & CAP & TEA & Selexol & TEA & TEA & Selexol \\
\hline Feed $\left[\mathrm{MW}_{t h, N G / B M}\right]$ & 559 & 587 & 588 & 725 & 725 & 725 & 380 & 380 \\
\hline $\mathrm{CO}_{2}$ capture $[\%]$ & 0 & 89.5 & 89.7 & 89.7 & 89.1 & 89.3 & 59 & 59 \\
\hline$\epsilon_{\text {tot }}[\%]$ & 58.75 & 49.6 & 50.9 & 56.8 & 52.6 & 53.3 & 34.8 & 34.8 \\
\hline & \multicolumn{8}{|c|}{ Power Balance } \\
\hline Net electricity $\left[\mathrm{MW}_{e}\right]$ & 328 & 291 & 299 & 408 & 375 & 381 & 132 & 132 \\
\hline$\dot{E}_{\text {Consumption }}^{+}\left[\mathrm{MJ}_{e} / \mathrm{GJ}_{e, n e t}\right]$ & - & 108.3 & 44 & 91.9 & 146.6 & 48.1 & 342.4 & 342.4 \\
\hline$\dot{E}_{\text {SteamNetwork }}^{-}\left[\mathrm{MJ}_{e} / \mathrm{GJ}_{e, n e t}\right]$ & 340.7 & 341.3 & 301 & 200 & 177.6 & 143.8 & 346.2 & 346.2 \\
\hline$\dot{E}_{\text {GasTurbine }}^{-}\left[\mathrm{MJ}_{e} / \mathrm{GJ}_{e, n e t}\right]$ & 659.3 & 767 & 743 & 891.9 & 969 & 904.3 & 996.2 & 996.2 \\
\hline & \multicolumn{8}{|c|}{ Economic Performance (Assumptions Table 9- Base) } \\
\hline Invest. $\left[\$ / \mathrm{kW}_{e}\right]$ & 555 & 909 & 785 & 757 & 813 & 798.8 & 7380 & 3880 \\
\hline COE no $\mathrm{CO}_{2}$ tax $\left[\$ / \mathrm{GJ}_{e}\right]$ & 18.31 & 23.7 & 22.5 & 22.67 & 24.5 & 24.1 & 66.1 & 49.5 \\
\hline $\mathrm{COE}$ with $\mathrm{CO}_{2}$ tax $\left[\$ / \mathrm{GJ}_{e}\right]$ & 22 & 24.2 & 22.8 & 23.0 & 24.9 & 24.5 & 60.2 & 43.6 \\
\hline Avoidance costs $\left[\$ / t_{C O 2, \text { avoided }}\right]$ & - & 60 & 43 & 46 & 66 & 62 & 173 & 113 \\
\hline & \multicolumn{8}{|c|}{ Environmental Performance $\left(\mathrm{FU}=1 \mathrm{GJ}_{e}\right)$} \\
\hline $\mathrm{CO}_{2}$ emissions $\left[\mathrm{kg}_{\mathrm{CO} 2} / \mathrm{GJ}_{e}\right]$ & 105 & 14.9 & 8.5 & 10.1 & 11.5 & 11.2 & -170.4 & -170.4 \\
\hline $\mathrm{IPCC}$ GWP $\left[\mathrm{kg}_{\mathrm{CO} 2, e q} / \mathrm{GJ}_{e}\right]$ & 120 & 34 & 27.7 & 30 & 31.9 & 36.1 & -139.6 & -134.2 \\
\hline EI99 $\left[\mathrm{pts} / \mathrm{GJ}_{e}\right]$ & 7.48 & 7.7 & 7.7 & 7.7 & 8.1 & 9.0 & 6.2 & 6.1 \\
\hline Impact $2002\left[10^{-3} \mathrm{pts} / \mathrm{GJ}_{e}\right]$ & 28.9 & 20.8 & 20.3 & 21.5 & 22.4 & 25 & 2.9 & 3.2 \\
\hline CML Acidification $\left[10^{-2} \mathrm{~kg}_{S O 2, e q} / \mathrm{GJ}_{e}\right]$ & 20.1 & 14.9 & 15.4 & 20.6 & 21.8 & 24.3 & 21.3 & 21.1 \\
\hline CML Eutrophication $\left[10^{-3} \mathrm{~kg}_{P O 4, e q} / \mathrm{GJ}_{e}\right]$ & 39 & 23.6 & 24.4 & 37.7 & 40.6 & 43.5 & 95.1 & 95 \\
\hline
\end{tabular}
rations.

Table 6: Performance of the different power plant options with $\mathrm{CO}_{2}$ capture. 

versus $\mathrm{CO}_{2}$ capture rate, bottom - $\mathrm{COE}$ (base economic scenario Table 9) versus $\mathrm{CO}_{2}$ capture rate.

Pre-combustion $\mathrm{CO}_{2}$ capture processes reveal to perform slightly better in terms of energy efficiency than post-combustion $\mathrm{CO}_{2}$ capture processes. In pre-combustion $\mathrm{CO}_{2}$ capture processes the energy demand for $\mathrm{CO}_{2}$ capture is lower, however the capital investment is larger because of the more complex installation. The electricity production costs are hence comparable for both concepts (Figure 8), since the higher productivity compensates the additional investment almost for the pre-combustion $\mathrm{CO}_{2}$ capture processes. $\mathrm{CO}_{2}$ capture in biomass fed processes leads to a lower electrical production efficiency and to higher costs due to the limited biomass conversion efficiency and to the high investment costs for the gasification process (Figure 8). However, these renewable processes have the advantage of capturing biogenic $\mathrm{CO}_{2}$ and will thus become interesting if a carbon tax is introduced. It has to be noted that the considered biomass plant's capacity of 380 $\mathrm{MW}_{t h, B M}$ is much lower than the one of the natural gas plants (580 and $725 \mathrm{MW}_{t h, N G}$ ). 
Table 7: Operating conditions for the different compromise power plant options with post-combustion $\mathrm{CO}_{2}$ capture, whose performance results are reported in Table 6 .

\begin{tabular}{|c|c|c|}
\hline System & $\begin{array}{c}\text { Post-comb } \\
\text { MEA }\end{array}$ & $\begin{array}{c}\text { Post-comb } \\
\text { CAP }\end{array}$ \\
\hline Lean solvent $\mathrm{CO}_{2}$ loading $[\mathrm{kmol} / \mathrm{kmol}]$ & 0.198 & 0.468 \\
\hline Rich solvent $\mathrm{CO}_{2}$ loading $[\mathrm{kmol} / \mathrm{kmol}]$ & 0.455 & - \\
\hline Rich solvent pre-heat $\mathrm{T}\left[{ }^{\circ} \mathrm{C}\right]$ & 100.12 & - \\
\hline Rich solvent re-heat $\mathrm{T}\left[{ }^{\circ} \mathrm{C}\right]$ & 122.71 & - \\
\hline LP stripper pressure [bar] & 1.926 & - \\
\hline HP / LP pressure ratio [-] & 1.357 & - \\
\hline MEA \% in solvent [-] & 0.337 & - \\
\hline Absorber steam out $\left[\mathrm{kg}_{H 2 O} / \mathrm{t}_{F G}\right]$ & 307.78 & - \\
\hline Split fraction [-] & 0.534 & - \\
\hline $\mathrm{Nb}$ stages absorber & 15.5 & - \\
\hline Nb stages HP stripper & 10.6 & - \\
\hline Nb stages LP stripper & 6.8 & - \\
\hline Absorber diameter $[\mathrm{m}]$ & 16.1 & - \\
\hline HP stripper diameter $[\mathrm{m}]$ & 5.6 & - \\
\hline LP stripper diameter $[\mathrm{m}]$ & 2.8 & - \\
\hline Absorber $\mathrm{T}_{\text {in }}[\mathrm{K}]$ & - & 278.27 \\
\hline Absorber Flash T $[\mathrm{K}]$ & - & 295.6 \\
\hline Stripper P [bar] & - & 39.07 \\
\hline
\end{tabular}

Table 8: Operating conditions for the different compromise power plant options with pre-combustion $\mathrm{CO}_{2}$ capture, whose performance results are reported in Table 6.

\begin{tabular}{|c|c|c|c|c|c|}
\hline System & $\begin{array}{l}\text { ATR } \\
\text { TEA }\end{array}$ & $\begin{array}{c}\text { ATR } \\
\text { Selexol }\end{array}$ & $\begin{array}{l}\text { SMR } \\
\text { TEA }\end{array}$ & $\begin{array}{l}\text { BM } \\
\text { TEA }\end{array}$ & $\begin{array}{c}\mathrm{BM} \\
\text { Selexol }\end{array}$ \\
\hline$\theta_{\text {wood,drying_out }}[\% \mathrm{wt}]$ & - & 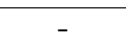 & - & 15 & 29 \\
\hline Gasification $\mathrm{T}[\mathrm{K}]$ & - & 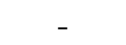 & - & 1123.1 & 1071.6 \\
\hline Gasification P [bar] & - & - & - & 3.5 & 1.58 \\
\hline Reforming $\mathrm{T}[\mathrm{K}]$ & 1289.3 & 1287.8 & 1339 & 1145 & 1196.5 \\
\hline Reforming P [bar] & 23.83 & 27.86 & 18.9 & - & - \\
\hline WGS $\mathrm{T}_{H T S}[\mathrm{~K}]$ & 636.35 & 650.29 & 631.97 & 637.04 & 683 \\
\hline $\mathrm{WGS} \mathrm{T}_{L T S}[\mathrm{~K}]$ & 423 & 428.39 & 515.33 & 534.03 & 567.99 \\
\hline WGS P [bar] & - & - & - & 6.61 & 6.7 \\
\hline $\mathrm{S} / \mathrm{C}[-]$ & 2.9 & 3.9 & 3.5 & 3.03 & 3.59 \\
\hline Flue gas $\mathrm{T}\left[{ }^{\circ} \mathrm{C}\right]$ & 41.34 & 40.2 & 31.2 & 29.77 & 20.97 \\
\hline Flue gas $\mathrm{P}\left[{ }^{\circ} \mathrm{C}\right]$ & 20.77 & 13.45 & 22.14 & 26.88 & 15 \\
\hline Absorber $\mathrm{T}\left[{ }^{\circ} \mathrm{C}\right]$ & 29.5 & -18 & 41.2 & 23.5 & 22.9 \\
\hline TEA concentration [\%wt] & 33.5 & - & 30.1 & 27.5 & - \\
\hline $\mathrm{H}_{2} /$ TEA ratio $[\mathrm{kg} / \mathrm{kg}]$ & 0.035 & - & 0.037 & 0.038 & - \\
\hline DEPG $/ \mathrm{CO}_{2}$ ratio $[\mathrm{kg} / \mathrm{kg}]$ & . & 12.3 & - & - & 11.34 \\
\hline Regeneration $\mathrm{T}\left[{ }^{\circ} \mathrm{C}\right]$ & 120 & 32 & 115.6 & 114.29 & 69.9 \\
\hline Regeneration $\mathrm{P}$ [bar] & 6.4 & 13.45 & 3.0 & 1.67 & 6.43 \\
\hline Turbine inlet $\mathrm{T}[\mathrm{K}]$ & 1537 & 1680 & 1500 & 1656 & 1648 \\
\hline
\end{tabular}

The biomass plant's scale is limited by the biomass availability and the logistics of wood transport, as explained in [20]. 


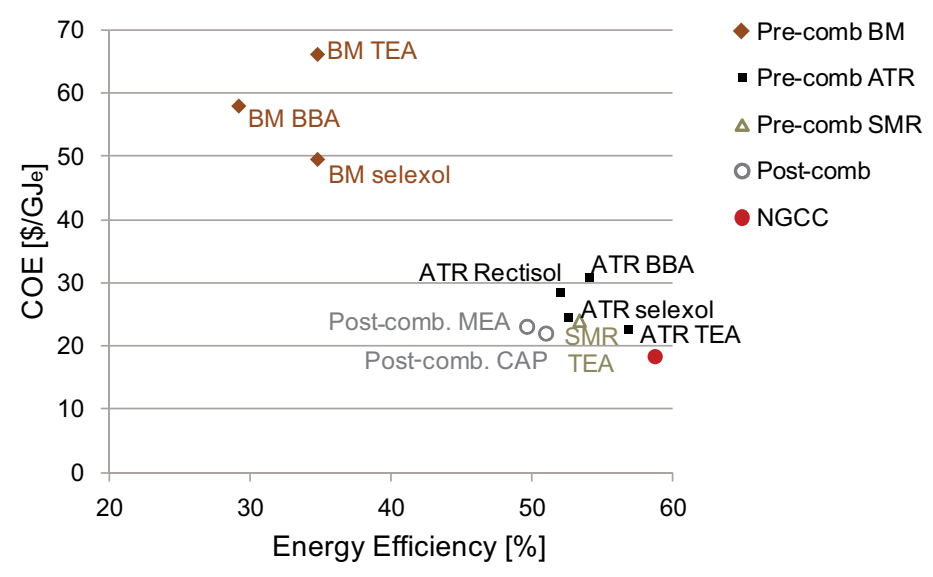

Figure 5: Performance results of the different power plant options with $\mathrm{CO}_{2}$ capture. For natural gas fed processes a capture rate of $90 \%$ is considered and $60 \%$ for biomass fed processes (Table 6).

\subsection{Environmental performance}

The climate change impact assessed with the IPCC 2007 method is detailed in Figure 6 for the different process options. The results reveal the benefit of capturing $\mathrm{CO}_{2}$ compared to a conventional NGCC plant without $\mathrm{CO}_{2}$ capture. For the natural gas fed processes, the major contributions to the greenhouse gas emissions are coming from the natural gas and from the uncaptured $\mathrm{CO}_{2}$. With $\mathrm{CO}_{2}$ capture, the contribution from the natural gas is slightly larger because of the lower power plant efficiency. For biomass fed processes, the advantage of capturing biogenic $\mathrm{CO}_{2}$ is revealed by the negative overall $\mathrm{CO}_{2}$ balance.

The damages assessed with the Impact 2002+ and Ecoindicator 99 method are reported in Figure 7. It is interesting to note that depending on the selected impact method, the $\mathrm{CO}_{2}$ capture options can have a higher or lower impact then the configurations without $\mathrm{CO}_{2}$ capture. With the Impact $2002+$ method, the overall environmental impact of the power plants with $\mathrm{CO}_{2}$ capture is lower than for the plants without capture due to the reduced climate change impact, even if the resources impact is increased. However, with the Ecoindicator-99 method, the overall impact of $\mathrm{CO}_{2}$ capture in a NGCC plant is $3 \%$ higher than without capture because of the impact on the depletion of fossil resources.

For natural gas based processes with $\mathrm{CO}_{2}$ capture, the impact on the resources is large since fossil resources are depleted. Due to the energy demand for $\mathrm{CO}_{2}$ capture and compression, the natural gas consumption is increased to produce 1 GJ of electricity compared to a conventional plant without $\mathrm{CO}_{2}$ capture having a higher productivity. For 


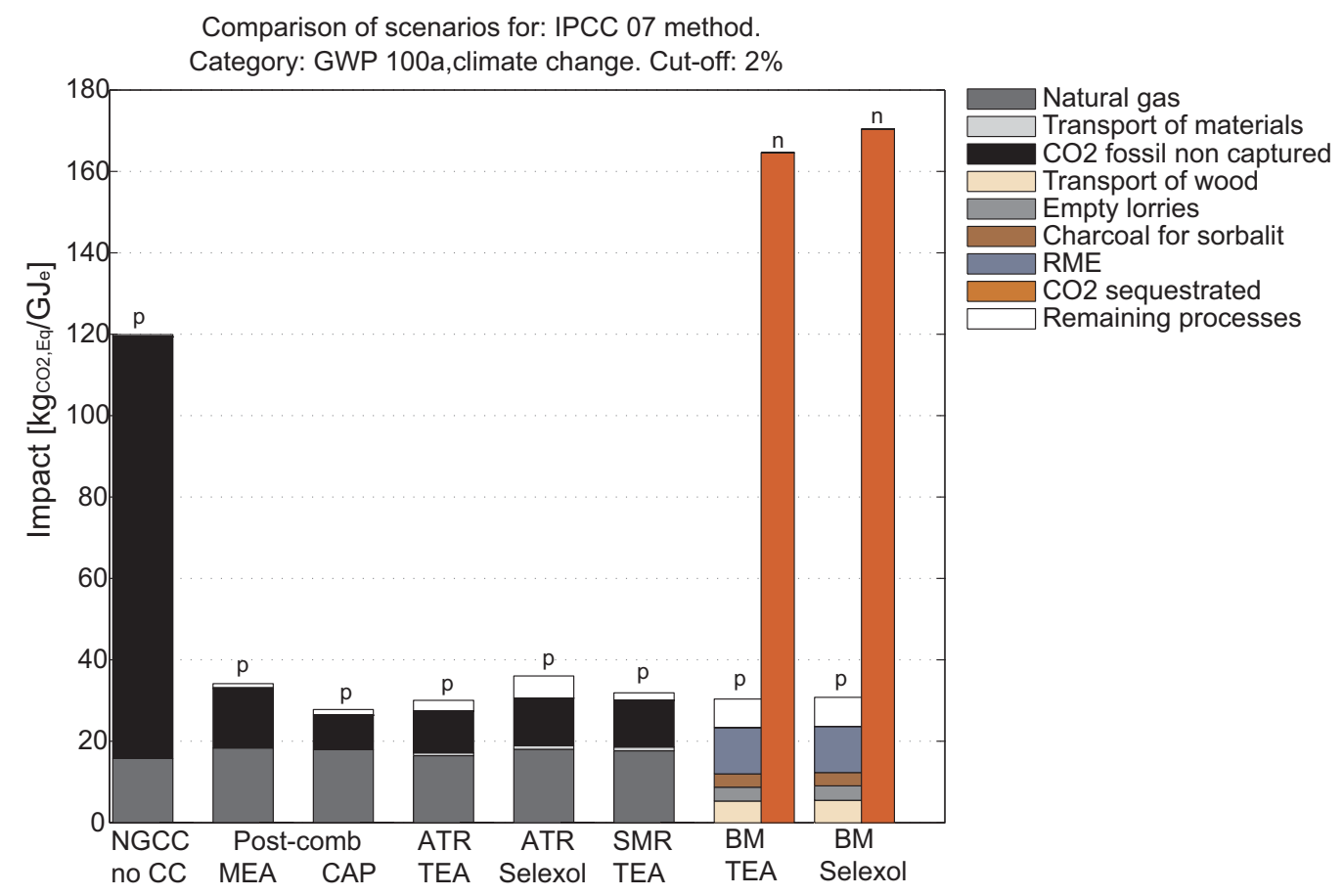

Figure 6: Comparison of the climate change impact of power plants without and with $\mathrm{CO}_{2}$ capture based on the impact method IPCC 07 for $1 \mathrm{GJ}_{e}$. Contributions that are harmful are labelled with a $p$ and beneficial ones with an $n$.
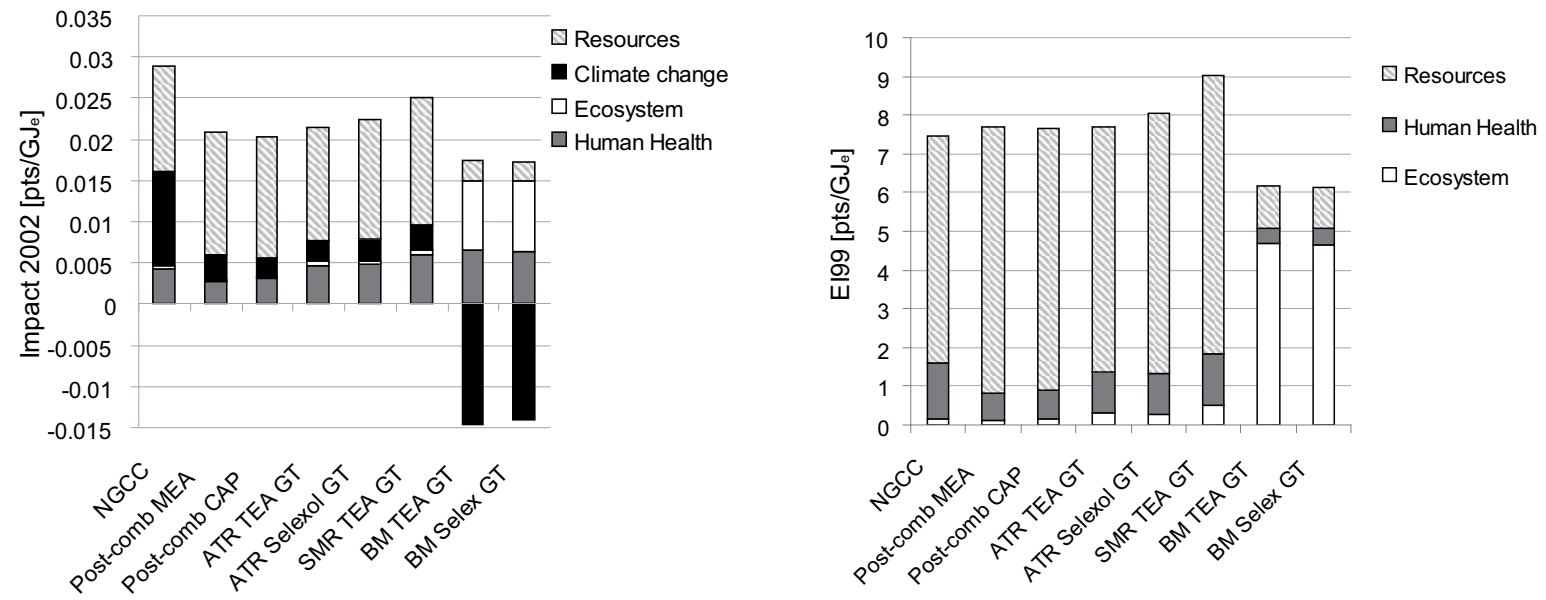

Figure 7: Comparison of the life cycle impacts of power plants without and with $\mathrm{CO}_{2}$ capture based on the impact methods Impact 2002+ (left) and Ecoindicator 99-(h.a) (right) for $1 \mathrm{GJ}_{e}$. Contributions that are harmful are positive and beneficial ones negative.

processes using biomass, which is a renewable resource, the impact on the resources is not significant, however the impact on the ecosystem is important. The usage of renewable resources, such as wood, influences of course the ecosystem. The largest contribution is however attributed to rape methyl ester (RME) consumed in the cold gas cleaning step. RME is produced from colza which is cultivated with insecticides. To reduce this impact alternative colza cultivation methods, the usage of other types of oils, and the development of alternative cleaning methods have to be investigated. Using renewable 
resources to produce ammonia will also considerably reduce the environmental impact as reported in [39].

The comparison of the environmental impacts of $\mathrm{CO}_{2}$ capture in power plants reveals the benefit of reducing greenhouse gas emissions on the climate change but also points out the difficulty of the single score life cycle assessment methods where the weighting factors may create biases in the analysis and thus lead to different conclusions. Considering different environmental impacts, no clear decision in favour of one specific capture concept can be made.

\subsection{Economic performance}

The economic competitiveness of $\mathrm{CO}_{2}$ capture highly depends on the resource price as shown in Figure 8. In fact, the costs are defined by up to $80 \%$ by the resource purchase.

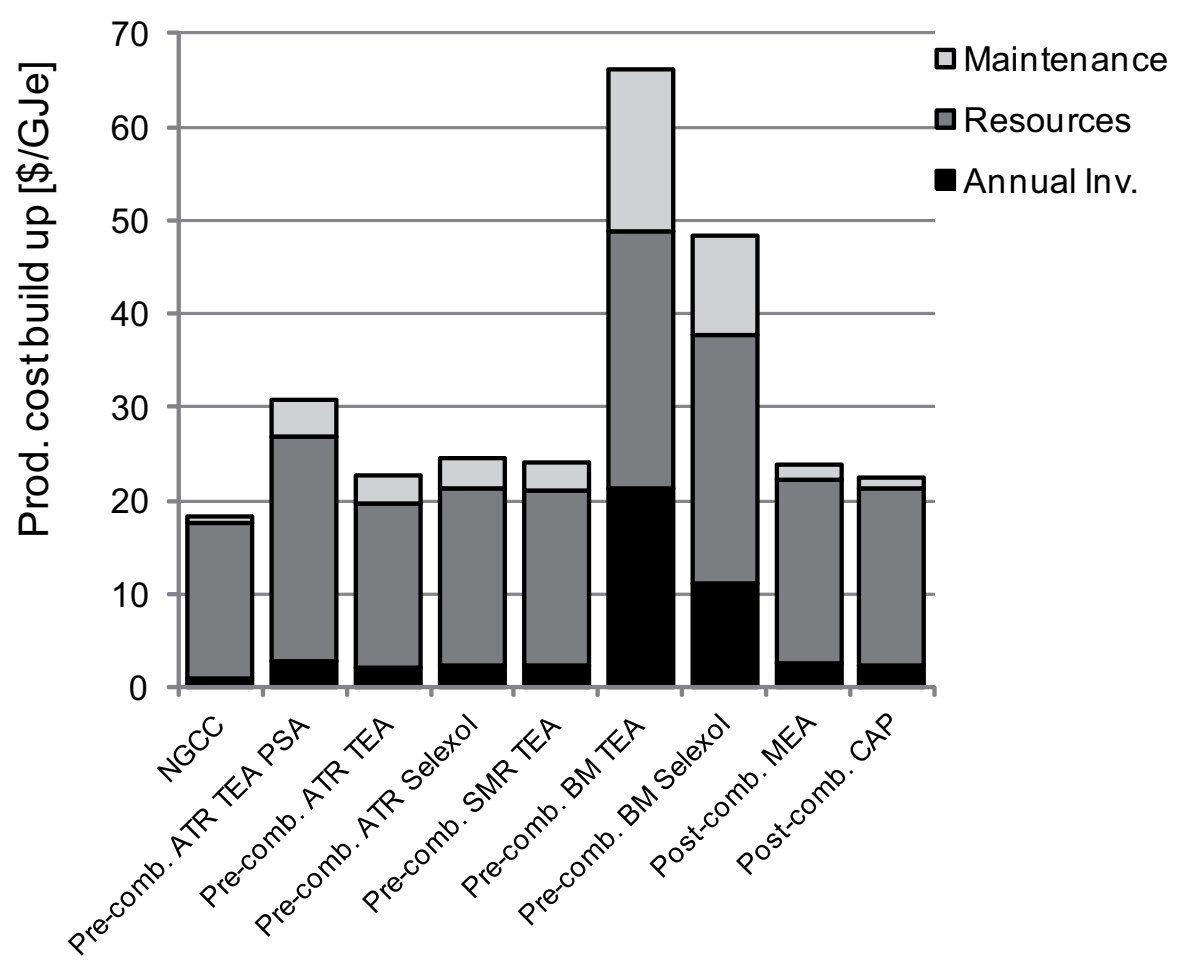

Figure 8: Production cost build-up (Base case economic scenario Table 9).

\subsubsection{Economic parameters sensitivity}

The variation of the electricity production costs with the resource purchase price and the introduction of a carbon tax is studied by sensitivity analyses in Figure 9 for the economic scenarios defined in Table 9. When a carbon tax of $35 \$ / t_{C O 2}$ is introduced, the economic benefit of a conventional NGCC is reduced and scenarios with $90 \%$ of $\mathrm{CO}_{2}$ 
capture become competitive (Figure 9 left). The break even natural gas price for which post-combustion $\mathrm{CO}_{2}$ capture becomes competitive is around $6 \$ / \mathrm{GJ}_{N G}$ for a carbon tax of $35 \$ / t_{\mathrm{CO} 2}$. Under the base case economic conditions, the break even carbon tax is around $50 \$ / \mathrm{t}_{\mathrm{CO} 2}$ for post-combustion capture with $\mathrm{MEA}$ and around $62 \$ / \mathrm{t}_{\mathrm{CO} 2}$ for pre-combustion capture with Selexol as shown in Figure 9 (right). Due to the benefit of capturing biogenic $\mathrm{CO}_{2}, \mathrm{CO}_{2}$ capture in biomass fed power plants becomes competitive with natural gas fed processes for a carbon tax of $62 \$ / t_{C O 2}$. In these analyses, the $\mathrm{CO}_{2}$ capture rate and thus the process design are fixed. However, it is evident that there is a trade-off between the economic performance and assumptions, and the process design, in particular the $\mathrm{CO}_{2}$ capture rate.

\begin{tabular}{|c|c|c|c|}
\hline Scenario & Base & High & Low \\
\hline Resource price $\left[\$ / G_{\text {res }}\right]$ & 9.7 & 14.2 & 5.5 \\
\hline Carbon tax $\left[\$ / t_{C O 2}\right]$ & 35 & 20 & 55 \\
\hline Yearly operation [h/year] & 7500 & 4500 & 8200 \\
\hline d lifetime [years] & 25 & 15 & 30 \\
\hline Inter & 6 & 4 & 8 \\
\hline feed $\left[\mathrm{MW}_{(t h)}\right]$ & 380 & 380 & 380 \\
\hline (post-comb) $\left[\mathrm{MW}_{(t h)}\right]$ & 725 & 725 & 725 \\
\hline NG feed (pre-comb) $\left[\mathrm{MW}_{(t h)}\right]$ & 590 & 590 & 590 \\
\hline
\end{tabular}
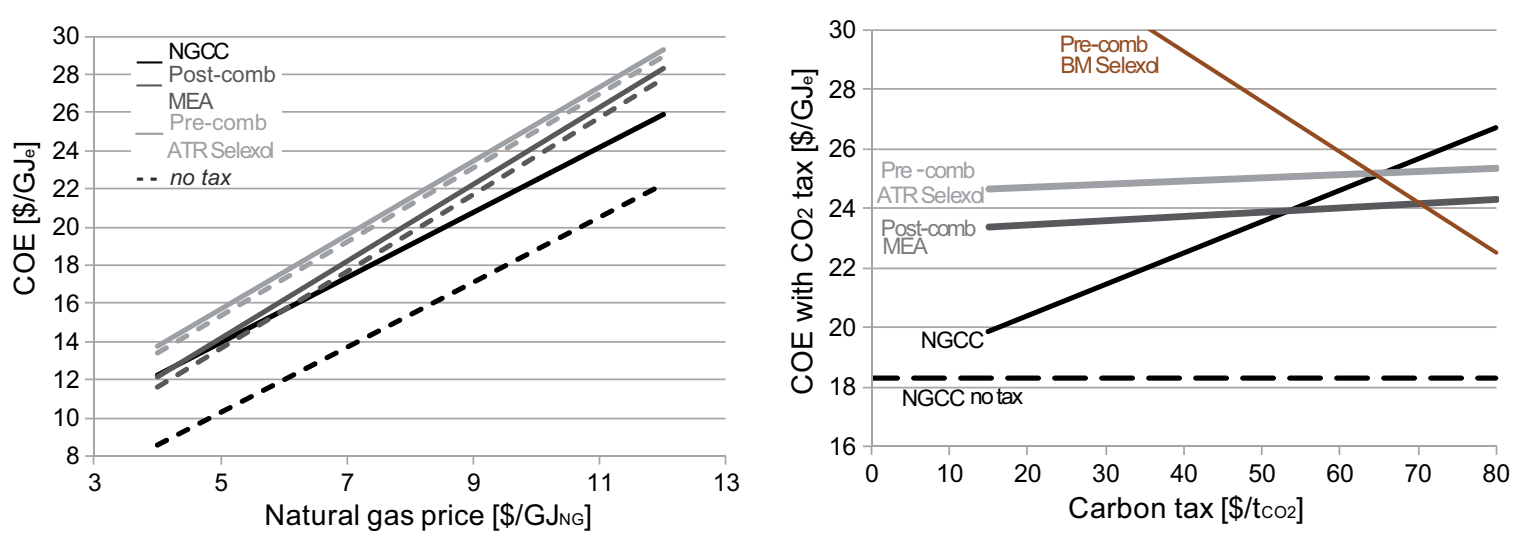

Figure 9: Left: Influence of the natural gas purchase price on the electricity production costs without (-) and with (-) the inclusion of a carbon tax of $35 \$ / \mathrm{t}_{\mathrm{CO} 2}$. Right: Influence of the carbon tax on the electricity production costs without and with $\mathrm{CO}_{2}$ capture for a natural gas price of $9.7 \$ / G J_{N G}$ and a biomass price of $5 \$ / \mathrm{GJ}_{B M}$.

\subsection{Decision making}

The previous results have revealed the trade-off between the different performance indicators and shown that the competitiveness and especially the economic performance of power plants with CCS is strongly determined by the economic conditions which are 
highly uncertain. This is highlighted in Figure 10. For the base case economic scenario biomass fed processes are not competitive and post-combustion $\mathrm{CO}_{2}$ capture performs best for capture rates around 70-85\%. When gas prices increase, the natural gas based processes become uncompetitive compared to the base case biomass configurations. From this Pareto frontiers it is difficult to identify the best process design.

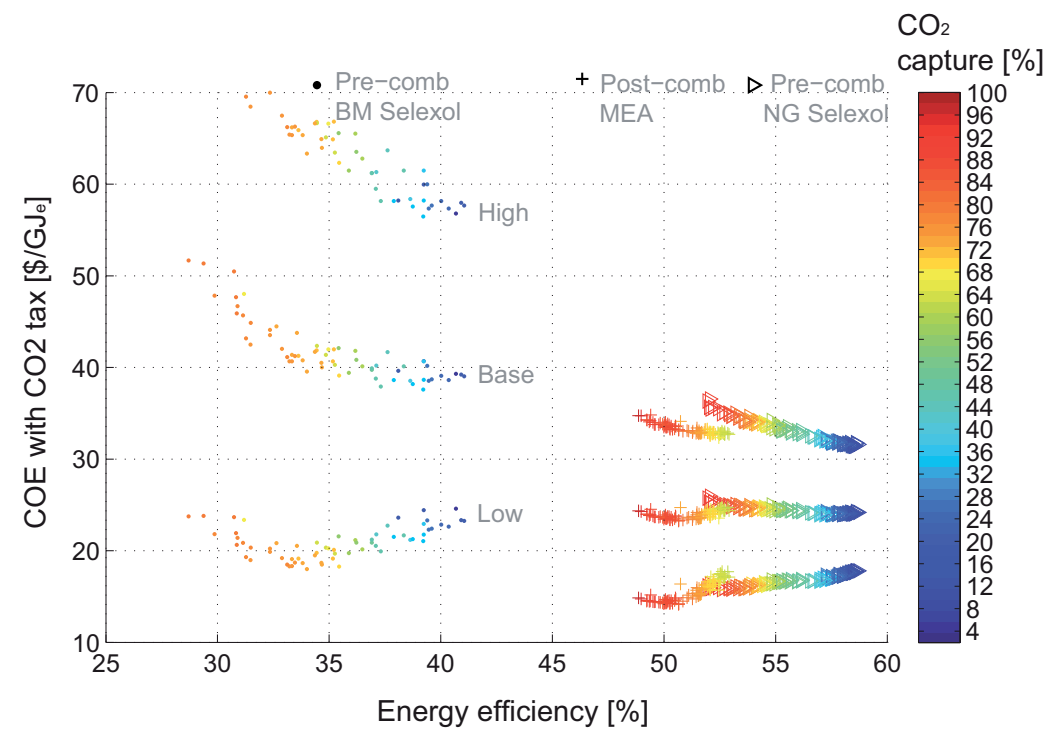

Figure 10: Multi-objective optimisation results: Performance of power plants with $\mathrm{CO}_{2}$ capture for different economic scenarios reported in Table 9.

The different process designs are ranked and the most economically competitive process designs are identified by applying the decision making approach on the Pareto-optimal solutions. Figure 11 illustrates the overall competitiveness of each Pareto-optimal solution compared to the most-economically competitive solution. The post-combustion process configuration capturing $83 \%$ of the $\mathrm{CO}_{2}$ emissions yields a relative competitiveness of 1 since this solution is the most economically competitive one in the large range of economic conditions. These results clearly show the close competition between post- and pre-combustion and underline that the $\mathrm{CO}_{2}$ capture rate is a key factor defining the economic performance. Pre-combustion $\mathrm{CO}_{2}$ capture configurations, being slightly more expensive for similar capture rates, yield however slightly better efficiencies. Depending on the production scope, this could affect decision-making for the more expensive solution. For some marginal economic scenarios $\mathrm{CO}_{2}$ capture in biomass fed power plants becomes a competitive alternative. In fact, the benefit from the carbon tax overweights the efficiency penalty for capture rates around $70 \%$. These results show how the most economically competitive process configurations can be identified from 
the Pareto-optimal solutions by applying the selection approach taking into account the economic conditions fluctuation.

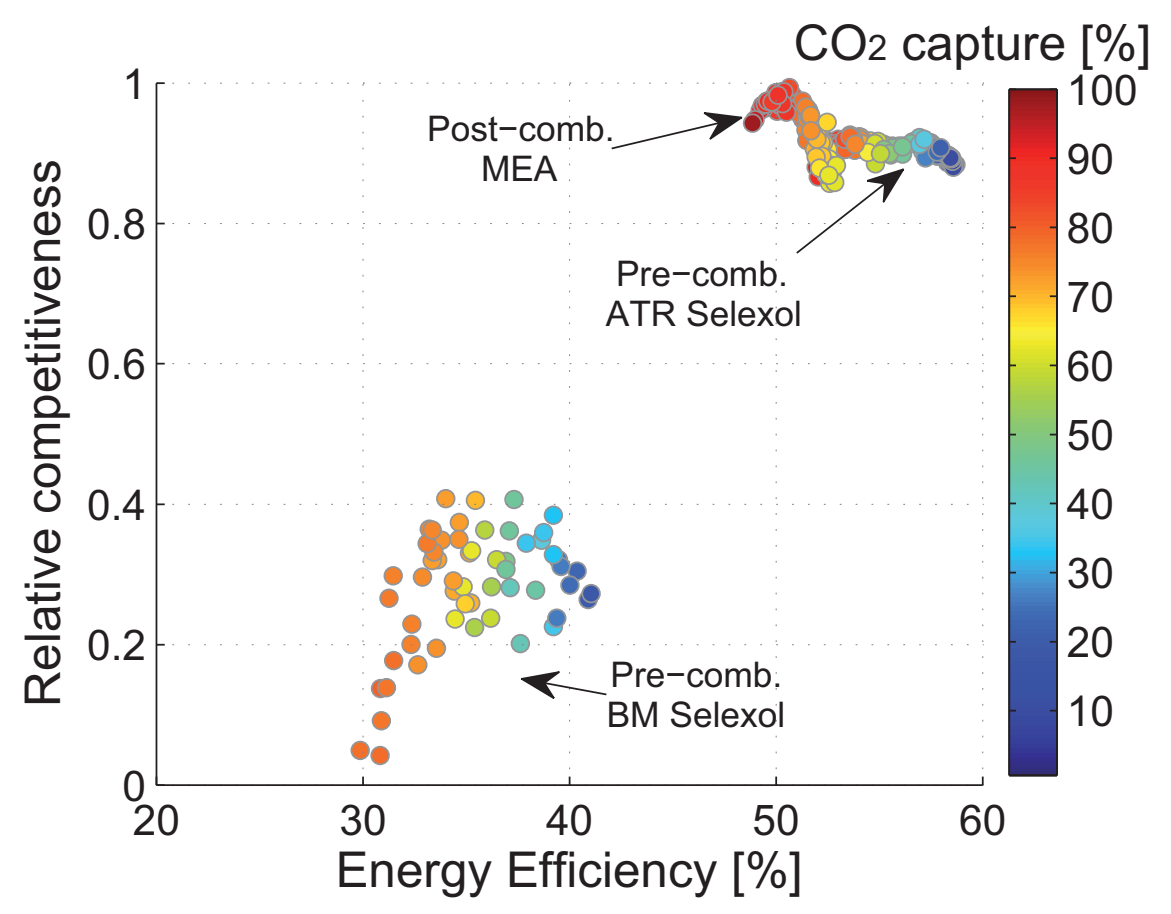

Figure 11: Relative competitiveness.

\section{Conclusions}

In the perspective of a sustainable energy future driven by greenhouse gas constraints, $\mathrm{CO}_{2}$ emissions have to be decreased, energy conversion efficiency has to be increased and fossil resources have to be progressively replaced by renewable resources. For the purpose of designing such complex integrated energy conversion systems and guiding decisionmaking and development, the systematic framework developed in this paper proves to be beneficial. The framework has the potential to be applied for studying all kinds of energy conversion systems. By expanding the superstructure with additional options, the energy market competitiveness can be accurately simulated with the aim of supporting decision-making. It turns out that process integration is a key point on which future developments have to focus.

Compared to natural gas fuelled power plants, $\mathrm{CO}_{2}$ capture in coal fired power plants results in slightly lower cost penalty due to the larger $\mathrm{CO}_{2}$ concentration in the flue gas. However, the energy penalty for $\mathrm{CO}_{2}$ capture and compression leads to an energy efficiency drop to $30 \%$ for the electricity generation. Looking at the thermodynamic performance, 
$\mathrm{CO}_{2}$ capture in biomass based plants can consequently compete with coal fired power plants. But coal fired power plants keep a big advantage with regard to the economic performance due to the low coal price. The specific $\mathrm{CO}_{2}$ emissions of coal fired power plants being more than twice as high as for natural power plants, $227 \mathrm{~kg}_{\mathrm{CO} 2} / \mathrm{GJ}_{e}$ compared to $103 \mathrm{~kg}_{\mathrm{CO} 2} / \mathrm{GJ}_{e}$, the introduction of a carbon tax will greatly penalise conventional coal fired power plants without $\mathrm{CO}_{2}$ capture. Consequently, the introduction of a carbon tax will favour CCS and renewable biomass based processes.

In the way towards a renewable future, $\mathrm{CO}_{2}$ capture and storage applied to $\mathrm{H}_{2}$ and power generation plants fuelled with fossil or renewable resources, appears to be a competitive transitional solution for mitigating climate change. To reliably establish the technology on a large scale, $R \& D$ efforts should continue to address the technology availability issues and focus on the reduction of the energy and cost penalty of CCS. 


\section{References}

[1] Metz B, Davidson O, de Coninck H, Loos M, Meyer L. IPCC special report on carbon dioxide capture and storage. Report; Cambridge University Press; 2005.

[2] Olajire AA. CO2 capture and separation technologies for end-of-pipe applications A review. Energy 2010;35(6):2610 -28.

[3] European Commission . Energy roadmap 2050. Communication from the Commission to the Council, the European Parliament, the European Economic and Social Committee and the Committee of Regions. SEC(2011) 1565/2; European Commission; 2011.

[4] Finkenrath M. Cost and performance of carbon dioxide capture from power generation. Report; International Energy Agency; 2011.

[5] ZEP . European Technology Platform for Zero Emission Fossil Fuel Power Plants. http://www.zeroemissionsplatform.eu/library.html; 2012.

[6] Figueroa JD, Fout T, Plasynski S, McIlvried H, Srivastava RD. Advances in CO2 capture technology-The U.S. Department of Energy's Carbon Sequestration Program. International Journal of Greenhouse Gas Control 2008;2(1):9-20.

[7] ZEP . The costs of CO2 capture, transport and storage - Post-demonstration CCS in the EU. Report; European Technology Platform; 2011. URL http://www .zeroemissionsplatform.eu/library.html.

[8] Rosen MA, Scott DS. Comparative efficiency assessments for a range of hydrogen production processes. International Journal of Hydrogen Energy 1998;23(8):653-9.

[9] Davison J, Arienti S, Cotone P, Mancuso L. Co-production of hydrogen and electricity with CO2 capture. International Journal of Greenhouse Gas Control 2010;4(2):125 -30 .

[10] Kvamsdal HM, Jordal K, Bolland O. A quantitative comparison of gas turbine cycles with CO2 capture. Energy 2007;32(1):10-24. 
[11] Cormos CC, Padurean A, Agachi PS. Technical evaluations of carbon capture options for power generation from coal and biomass based on integrated gasification combined cycle scheme. Energy Procedia 2011;4(0):1861-8.

[12] Berstad D, Arasto A, Jordal K, Haugen G. Parametric study and benchmarking of NGCC, coal and biomass power cycles integrated with MEA-based post-combustion CO2 capture. Energy Procedia 2011;4(0):1737-44.

[13] Liew PY, Varbanov PS, Bulatov I, Perry SJ, Gharaie M, Zhang N, et al. Identification of process integration options for carbon capture. In: Jiri Klemes ${ }^{\circ}$ PSV, Liew PY, editors. 24th European Symposium on Computer Aided Process Engineering; vol. 33 of Computer Aided Chemical Engineering. Elsevier; 2014, p. 1873 -8.

[14] Klemes J, Bulatov I, Cockerill T. Techno-economic modelling and cost functions of co2 capture processes. Computers \& Chemical Engineering 2007;31(5-6):445 -55.

[15] Bartels JR, Pate MB, Olson NK. An economic survey of hydrogen production from conventional and alternative energy sources. International Journal of Hydrogen Energy 2010;35(16):8371-84.

[16] Viebahn P, Nitsch J, Fischedick M, Esken A, Schüwer D, Supersberger N, et al. Comparison of carbon capture and storage with renewable energy technologies regarding structural, economic, and ecological aspects in germany. International Journal of Greenhouse Gas Control 2007;1(1):121-33.

[17] Volkart K, Bauer C, Boulet C. Life cycle assessment of carbon capture and storage in power generation and industry in Europe. International Journal of Greenhouse Gas Control 2013;16:91-106.

[18] Dufour J, Serrano DP, Gálvez JL, González A, Soria E, Fierro JL. Life cycle assessment of alternatives for hydrogen production from renewable and fossil sources. International Journal of Hydrogen Energy 2012;37(2):1173 -83.

[19] Gassner M, Maréchal F. Methodology for the optimal thermo-economic, multiobjective design of thermochemical fuel production from biomass. Computers \& Chemical Engineering 2009;33(3):769-81. 
[20] Gerber L, Gassner M, Maréchal F. Systematic integration of LCA in process systems design: Application to combined fuel and electricity production from lignocellulosic biomass. Computers \& Chemical Engineering 2011;35(7):1265 -80.

[21] MathWorks Inc. . MATLAB, last visited 12/2012. http://www.mathworks.ch/.

[22] Tock L, Maréchal F. Platform development for studying integrated energy conversion processes: Application to a power plant process with CO2 capture. In: Karimi I, Srinivasan R, editors. Proceedings of the 11th International Symposium on Process Systems Engineering - PSE 2012. Computer-aided Chemical Engineering; Elsevier; 2012d, p. 1015-9.

[23] Molyneaux A, Leyland G, Favrat D. Environomic multi-objective optimisation of a district heating network considering centralized and decentralized heat pumps. Energy 2010;35(2):751-8.

[24] Belsim S.A. . last visited 12/2012. http://www.belsim.com.

[25] AspenTech . Aspen Technologies Inc., last visited 12/2012. http://www.aspentech.com.

[26] Maréchal F, Kalitventzeff B. Process integration: Selection of the optimal utility system. Computers \& Chemical Engineering 1998;22:149-56.

[27] Turton R. Analysis, Synthesis, and Design of Chemical Processes. Upper Saddle River, N.J: Prentice Hall; 3rd ed ed.; 2009.

[28] Ulrich G, Vasudevan P. A Guide to Chemical Engineering Process Design and Economics a Practical Guide. Boca Raton, Fla: CRC; 2nd ed ed.; 2003.

[29] Ecoinvent . http://www.ecoinvent.ch/; last visited 12/2012.

[30] IPCC . Climate change 2007: the scientific basis. Report; Intergovernmental Panel on Climate Change, In: Fourth assessment report of the intergovernmental panel on climate change (2007); 2007.

[31] Goedkoop M, Spriensma R. The eco-indicator 99: a damage oriented method for life cycle impact assessment. Report; Amersfoort, The Netherlands: PRÈ Consultants; 2000. 
[32] Tock L, Maréchal F. Decision Support for CO2 Capture Process Options under Uncertain Market Conditions using Multi-objective Optimisation. In: Jiri Klemes ${ }^{\circ}$ PSV, Liew PY, editors. 24th European Symposium on Computer Aided Process Engineering; vol. 33 of Computer Aided Chemical Engineering. Elsevier; 2014b, p. $1207-12$.

[33] Urech J, Tock L, Harkin T, Hoadley A, Maréchal F. An assessment of different solvent-based capture technologies within an igccñccs power plant. Energy $2014 ; 64(0): 268-76$.

[34] Tock L, Maréchal F. Co-production of hydrogen and electricity from lignocellulosic biomass: Process design and thermo-economic optimization. Energy 2012a;45(1):339 $-49$.

[35] Tock L, Maréchal F. H2 processes with CO2 mitigation: Thermo-economic modeling and process integration. International Journal of Hydrogen Energy 2012b;37(16):11785-95.

[36] Tock L, Maréchal F. Process design optimization strategy to develop energy and cost correlations of co2 capture processes. Computers \& Chemical Engineering 2014;61(0):51 -8.

[37] Bernier E, Maréchal F, Samson R. Multi-objective design optimization of a natural gas-combined cycle with carbon dioxide capture in a life cycle perspective. Energy 2010;35(2):1121-8.

[38] Gal E. Ultra cleaning of combustion gas including the removal of CO2. Patent WO/2006/022885; 2006.

[39] Tock L, Maréchal F, Perrenoud M. Evaluation thermo-environomique de la production d' ammoniac. XIVe congrès de la Société Française de Génie des Procédés, October 2013, Lyon, France; $2012 f$. 